\title{
EL JEFE DE LA POLICIA MUNICIPAL: ANALISIS DE SUS FUNCIONES Y DE SUS EXIGENCIAS
}

\author{
352.745 .5
}

por

\section{Julián Carrasco Belinchón}

SUMario: I. INTRoduccion: 1. Planteamiento. 2. Objetivo. 3. Plan DE EXPOSICIÓN.-II. LA TRIPLE FIGURA DEL ALCALDE Y SU INCIDENCIA EN EL JEFE DE LA POLICIA MUNICIPAL: 1. LA triple figura del Alcalde. 2. La incidencia en el Jefe de la Policfa Municipal: A) El Alcalde como Delegado del Gobierno. B) El Alcalde como Presidente del Ayuntamiento. C) El Alcalde como Jefe de la Administración municipal. D) Conclusión.-III. LA ACTUACION DEL JEFE DE LA POLICIA MUNICIPAL: 1. PlanteaMIENTO. 2. Normas Generales: A) Saber. B) Saber hacer. C) Saber ser: a) Como ciudadano. b) Como funcionario municipal. c) Como Jefe de la Policía Municipal. 3. Normas especfficas: A) En el plano del orden público. B) En la esfera de las funciones representativas. C) En el ámbito de la ordenación del tráfico, de la vigilancia del cumplimiento de las Ordenanzas municipales y del fomento de la armónica convivencia ciudadana.--IV. EL JEFE DE LA POLICIA MUNICIPAL Y LAS RELACIONES PUBLICAS MUNICIPALES.-V. CONCLUSIONES.

\section{INTRODUCCION}

\section{Planteamiento}

Del conjunto de los servidores locales se pueden destacar, por su cometido, algunos grupos específicos que presentan peculiaridades propias claramente diferenciadas y que merecen tratamiento 
individualizado. Dentro de estos grupos, a su vez, ocupan un lugar relevante, por la trascendencia de su misión, los integrantes de la Policía Municipal, que si bien han sido objeto de múltiples estudios, fundamentalmente, desde el punto de vista jurídico y también desde la perspectiva orgánica, no obstante, creemos que una faceta que no ha sido suficientemente tratada es, precisamente, la resultante de contemplarla conjuntamente desde el prisma organizativodirectivo y desde él de las Relaciones Públicas. Faceta que presenta aspectos de un acusado interés y que requieren una especial atención, por cuanto pueden proporcionar una visión global de la problemática privativa de este grupo de funcionarios.

\section{OBJETIVo}

Nuestro propósito en este caso es, precisamente, analizar desde este enfoque tal problemática, tomando como centro de atención a la figura del Jefe de la Policía Municipal, por cuanto concebimos a éste como pieza clave en el funcionamiento de los servicios municipales y, al mismo tiempo, lo consideramos como piedra angular para la convivencia armónica municipal.

Si esto es así, y lo creemos firmemente, es evidente que resulta esencial que quienes ocupan los puestos de Jefes de la Policía Municipal conozcan cuál es su cometido y lo sepan desempeñar con eficacia, pues su actuación entraña hondas y profundas repercusiones en la vida cotidiana local. Nos consta, por otra parte, que de ordinario quienes desempeñan tal cargo saben desarrollar su papel en forma satisfactoria, lo cual no es impedimento para que expongamos a continuación las líneas maestras de su conducta, pues de esta forma tendrán la ocasión de contrastarlas con su comportamiento diario, comprobando que está en línea con estas directrices. $\mathrm{Y}$ al mismo tiempo se brinda la oportunidad de reconocer lo meritorio de su labor y lo beneficioso de su trabajo para la comunidad municipal (1).

(1) En la redacción de este trabajo hemos tenido como material básico las ideas expuestas en la conferencia pronunciada en abril de 1974 en Zafra, dentro de las IV Jornadas Extremeñas de Jefes de Policía Municipal y Tráfico Urbano. 


\section{Plan DE EXPOSICIÓN}

En base a este propósito, el trabajo lo dividimos en los siguientes epígrafes: en el primero, y como punto de partida, examinaremos la triple figura del Alcalde y su incidencia en el Jefe de la Policía Municipal; en el segundo examinaremos las exigencias de la actuación del Jefe de la Policía Municipal; en el tercero contemplaremos el papel de éste ante la política de Relaciones Públicas municipales $\mathrm{y}$, en el último, como Conclusiones, sintetizaremos las principales ideas expuestas.

\section{LA TRIPLE FIGURA DEL ALCALDE Y SU INCIDENCIA EN EL JEFE DE LA POLICIA MUNICIPAL}

\section{LA TRIPLE Figura DEL AlCalde}

La Ley de Régimen local y su Reglamento de Organización, Funcionamiento y Régimen jurídico configuran a la primera autoridad municipal en una triple dimensión: como Delegado del Gobierno en el término municipal, como Presidente de la Corporación y como Jefe de la Administración municipal.

Cada una de estas tres dimensiones presenta su específica problemática, y si se contemplan conjuntamente, entonces nos proporcionan una visión integral de la figura compleja, apasionante y admirable del Alcalde. Ahora bien, como ésta ha sido objeto de diferentes estudios monográficos, $\mathrm{y}$, por otra parte, nuestro propósito no es analizarla ahora y sí sólo tenerla en cuenta como punto de partida para el examen que vamos a realizar, estimamos que es suficiente con mencionar simplemente estas tres dimensiones, sin necesidad de verificar una exégesis de su contenido típico y fundamental.

En cambio, para el propósito que nos anima reviste un interés más acusado contemplar la incidencia de esta configuración tridimensional en el Jefe de la Policía Municipal, por cuanto delimita el contorno de la actuación de dicho Jefe y sobre todo condiciona el talante de su comportamiento específico y concreto. 
2. La incidencia en el Jefe de la Policfa Municipal

\section{A) El Alcalde como Delegado del Gobierno.}

La primera dimensión se proyecta, fundamentalmente, en la actuación del Jefe de la Policía Municipal con respecto al orden público. Actividad que será más o menos relevante y trascendente, según que no existan en el término municipal otros Agentes de Seguridad, o que estando destacados en ella, ya pertenezcan a la Guardia Civil, a la Policía Armada o al Cuerpo General de Policía. En el primer supuesto es evidente que la ausencia de estos Agentes determina que el papel de la Policía Municipal, y en especial de su Jefe, sea de protagonista estelar en este campo, en tanto que en el segundo supuesto su misión se reduce a la de colaborador y auxiliar de aquellos Agentes. Pero tanto en uno como en otro caso, hay que reconocer la importancia del cometido del Jefe de la Policía - Municipal, en cuanto a la vigilancia del orden público, como responsabilidad trascendente del Alcalde.

\section{B) El Alcalde como Presidente del Ayuntamiento.}

La segunda dimensión se manifiesta en el plano representativo de la Corporación, en el que el Jefe de la Policía Municipal personifica el símbolo externo de la autoridad corporativa. Es a través de él como se exterioriza el poder que reside en el Ayuntamiento, de tal forma que podríamos decir que el Jefe de la Policía Municipal es el testimonio vivo de las atribuciones conferidas a la Corporación. Efectivamente, éstas se actúan y materializan mediante la Policía Municipal, que las plasma en la realidad en el ejercicio de sus funciones privativas.

\section{C) El Alcalde como Jefe de la Administración municipal.}

La tercera dimensión es, sin duda, cuantitativa y cualitativamente la más trascendente, y su incidencia en el Jefe de la Policía se proyecta en tres áreas distintas y complementarias:

- la regulación del tráfico de vehículos y peatones; 
- la vigilancia del cumplimiento de las Ordenanzas municipales, y

- el fomento de la convivencia armónica vecinal.

\section{D) Conclusión.}

Se puede afirmar, pues, que, en síntesis, el Jefe de la Policía Municipal:

1. Asume la honrosa misión de representar a la autoridad municipal ante los vecinos, ante los visitantes y ante los turistas.

2. Al mismo tiempo, recae sobre él la gran responsabilidad de que el contacto y la relación de estos grupos con la Corporación municipal, fuera de la Casa Consistorial y al margen de los servicios municipales en concreto: Saneamiento, Mercados, Mataderos, Sanidad, etc., sea satisfactoria.

En definitiva, el Jefe de la Policía Municipal y sus Agentes son, como se ha anticipado, la personificación de la autoridad municipal, y simultáneamente son el signo externo y más visible de la misma. De tal forma, que es evidente que el modo en que se desenvuelva la relación con el público en general producirá en éste una impresión positiva o negativa de la actividad municipal. En consecuencia, el Jefe de la Policía Municipal y sus Agentes constituyen un factor esencial para la creación de una imagen favorable de dicha actividad, o, por otro lado, pueden contribuir a que el concepto que de la misma tenga el público sea francamente negativo.

\section{LA ACTUACION DEL JEFE DE LA POLICIA MUNICIPAL}

\section{Planteamiento}

¿Cómo tiene que actuar el Jefe de la Policía Municipal para provocar esa impresión favorable? Si bien los Jefes de la Policía Municipal, de ordinario, con su conducta diaria, nos están enseñando cuáles son las características de dicha actuación, y en el ánimo de todos está el mejorarla y perfeccionarla, no obstante, y con el fin no de indicar cuál es el comportamiento ideal -que, insistimos, lo suelen conocer y lo practican habitualmente-, sino de poner de relieve la grandeza de su misión y el esfuerzo que entraña cumplirla 
correctamente, a continuación vamos a exponer un esquema del ideario de la actuación del Jefe de la Policía Municipal. Ideario extraído de la práctica y asentado en la doctrina. Ideario que, repetimos, cotidianamente es de todos los Jefes de la Policía Municipal conocido, vivido y practicado normalmente. $Y$ en él podemos diferenciar, por una parte, las normas generales de conducta $\mathrm{y}$, por otra, las específicas a cada una de las áreas en las que se proyectan las tres dimensiones mencionadas de la figura del Alcalde (2).

\section{NORMAS GENERALES}

Como cuestión previa hay que reconocer, como ha puesto de relieve la doctrina, y en este sentido podemos acudir a la opinión autorizada de A. Pinilla, que "la acción de la dirección ha de caracterizarse porque quien la realiza actúa sabiendo y sabe actuar. Actuar sabiendo es ser lo suficientemente sensato como para no tomar decisiones sin poseer los conocimientos y la información adecuada. El tráfago de la acción cotidiana es tan dinámico, absorbente, cambiante y estimulante, que muchas veces prevalecen en la acción las reacciones emotivas, sentimentales o instintivas. Se actúa habitualmente guiado más por el sentimiento y las emociones, tristeza o alegría, ánimo agresivo o cooperativo, que nunca debe ser el elemento rector de las reacciones y conducta del Jefe.

Hacer sabiendo quiere decir - concluye- actuar de acuerdo a normas y principios y no de acuerdo a caprichos, emociones pasajeras o estados afectivos o tendencias instintivas, anímicamente condicionaras por circunstancias específicas. El nepotismo y la tiranía son formas de conducta mucho más corrientes de lo que se cree. El comportamiento sereno, equilibrado y racional que obedece a ideas y a principios es propio del buen dirigente, pero es algo difícil de encontrar» (3). En consecuencia, podemos afirmar por nuestra parte que la actuación del Jefe de la Policía Municipal debe ser conforme al tríptico de saber, saber hacer y saber ser. Analicemos por separado cada uno de estos aspectos, pues en ellos radica la esencia del comportamiento ideal.

(2) Como complemento y ampliación de las ideas que se contienen en este epígrafe, se puede acudir a J. Rojo Gil y P. Martfnez Robles, en Guía de la Policía Municipal, Madrid, 1974, págs. 81 a 192.

(3) Principios de las relaciones sociales y administrativas, Barcelona, 1972, página 311 . 


\section{A) Saber.}

El Jefe de la Policía Municipal ha de tener una idea nítida de cuál es su misión, lo que es tanto como conocer sus obligaciones y sus responsabilidades en primer término, y sus derechos y prerrogativas en segundo lugar. Se precisa, en consecuencia, que domine bien su campo de competencia, para lo cual ha de esforzarse, por los medios que estén a su alcance, por adquirir nuevos conocimientos, por ampliar los que posee y por profundizar en ellos. El Jefe de la Policía Municipal no ha de olvidar que el saber es poder y que el saber es valer. Ha de tener presente, en definitiva, que, de ordinario, vale y puede cuanto sabe. A este respecto, no hay que olvidar que, como advierten K. H. Blanchard y P. HERSEY, «las personas buscan prestigio a lo largo de sus vidas de diversas maneras. Muchos tienden a buscar solamente los símbolos materiales de la posición, mientras que otros se esfuerzan por obtener un logro personal o una realización personal que impongan prestigio por sí solos. Independientemente de la manera en que se exprese, parece estar muy extendida la necesidad que siente la gente de que se aclare su importancia y se sitúe al nivel que cada quien cree merecer. Las personas normalmente desean tener una alta valoración de sí mismas, que esté firmemente basada en la realidad, según como se manifieste por el reconocimiento y el respeto que le conceden los demás" (4). Pues bien, esta alta valoración y este reconocimiento se asientan en gran parte en los conocimientos que se poseen y en el empleo adecuado que de los mismos se hace.

Por otra parte, no se puede ignorar que las mutaciones y cambios de la vida actual, con sus transformaciones rápidas, continuas y trascendentes, demandan un constante estudio para estar al día, pues en otro caso quedamos marginados a las exigencias de la hora presente. Precisamente para satisfacer estas exigencias se ha implantado la educación permanente, que responde a un estado de ánimo de afán constante de adquirir nuevos conocimientos y de desarrollar las aptitudes que se poseen. Ejemplo de este afán son los cursos de capacitación para mandos de la Policía de poblaciones importantes que hemos celebrado en la Escuela Nacional de Administración Local, y manifestación también lo es el curso que

(4) La Administración y el comportamiento humano, México, 1970, pág. 42. 
actualmente estamos desarrollando de Enseñanza a Distancia para Jefes de Municipios de 15.000 a 50.000 habitantes, al que seguirá en fecha próxima el correspondiente a Jefes de Municipios de 8.000 a 15.000 habitantes.

\section{B) Saber hacer.}

Ahora bien, no es suficiente con que el Jefe de la Policía Muni cipal sepa, es preciso que además sepa hacer, y'esto, de ordinario, es mucho más difícil, pues no sólo se trata de un problema cuantitativo: sepa hacer todo lo que le corresponde, sino que es también, y sobre todo, una cuestión cualitativa: lo sepa hacer bien, en precisión, en exactitud y en presentación. Es decir, ser eficaz, y, como nos dice Duval, "el ser eficaz comienza por el conocimiento de sí mismo y de los demás, por un esfuerzo de lucidez para estar en condiciones de saber a dónde se va. Partiendo de ello, en el ámbito del conocimiento se injerta toda una serie de prácticas eficaces que mejoran nuestro rendimiento personal y sobre todo nos evitan recaer en ciertos errores comunes» (5).

En conclusión, el Jefe de la Policía Municipal, si como Policía ha de actuar bien, como Jefe ha de actuar aún mejor. Su conducta ha de ser modelo en la que se miren y contemplen los que de él dependen. Su comportamiento, además, servirá de base para juzgar igualmente a sus hombres. En consecuencia, el saber hacer es un compromiso ineludible del Jefe de la Policía Municipal, y sólo en la medida en que lo cumpla a satisfacción podrá considerarse como auténtico Jefe. Las manifestaciones y modalidades que adopta este "saber hacer", evidentemente, son varias y distintas, y a las principales nos referiremos a continuación, al exponer las normas específicas.

\section{C) Saber ser.}

Por último, el Jefe de la Policía precisa, además, y sobre todo, saber desempeñar bien su triple papel: como ciudadano, como funcionario municipal y como Jefe de la Policía Municipal.

(5) La eficacia personal en la empresa, Barcelona, 1973, pág. 134. 


\section{a) Como ciudadano.}

El Jefe de la Policía Municipal, como ciudadano, es decir, como miembro de la comunidad vecinal, ha de ser modelo en el cumplimiento de sus obligaciones cívicas, por cuanto es observado y valorado con detenimiento por todos sus convecinos. De aquí el que cualquier fallo o deficiencia sea siempre detectado y criticado detenidamente. $\mathrm{Y}$ por otra parte, la conducta ejemplar es, de ordinario, admirada y reconocida por dichos convecinos. En conclusión, el Jefe de la Policía Municipal ha de tener presente que es un vecino con muchas obligaciones y con más servidumbres durante las veinticuatro horas del día y durante los trescientos sesenta y cinco días del año, salvo que pueda disfrutar de vacaciones y se ausente del término municipal.

\section{b) Como funcionario municipal.}

El Jefe de la Policía, como funcionario municipal, ha de ser siempre un servidor incansable, dispuesto a actuar en todo instante, momento y circunstancia. Tiene que ser, por tanto:

1. Incansable en su labor.

2. Con gran imaginación para hallar solución a las múltiples cuestiones que se presentan de improviso.

3. Con tesón para salir adelante.

A este respecto, ha de tener presente que, como advierte M. R. FEINBERG, "en la vida hay muchos aspectos dolorosos, desagradables o que implican algún desengaño. Las personas maduras tampoco pueden escapar a estos inconvenientes. Sin embargo, los hombres maduros reaccionan ante estos golpes en la vida con la esperanza y ductilidad. Saben que no todo puede salir bien, y aceptan el hecho de que debe haber contrariedades y se deben cometer errores, y no pierden el tiempo lamentándose de las cosas pasadas. Fallos y tropiezos que tal vez hundirían a otras personas, son considerados simplemente como lecciones por parte del hombre maduro»(6). En definitiva, el Jefe de la Policía Municipal, como hom-

(6) Psicologia efectiva para directores y jefes, Barcelona, 1970, pág. 72. 
bre maduro, hà de ser inasequible al desaliento, con mente creadora y con voluntad firme y constante. De él se ha de poder decir que lo fácil lo hace sobre la marcha; lo difícil le cuesta más trabajo y lo imposible requiere de él más tiempo, pero nada de lo que se le encarga queda sin hacer y sin hacer bien.

\section{c) Como Jefe de la Policía Municipal.}

El Jefe de la Policía, por último, en su condición de tal Jefe, tiene que ser lcal y obediente a la Superioridad, conductor de sus hombres, respetuoso con el público e ilusionado con su misión. Veamos cada una de estas exigencias (7).

1. Leal con la Superioridad, a la que ha de seguir escrupulosamente y con la mayor atención y detalle. El Jefe de la Policía ha de ser siempre fiel a la autoridad municipal, con la que ha de sentirse compenetrado y unido, independientemente de que comparta o no los puntos de vista de quienes en cada momento la detentan. $\mathrm{Ha}$ de tener presente en todo instante que es a las Instituciones, no a las personas, a las que sirve y a las que se debe.

2.a Obediente a dicha autoridad, lo que significa que ha de ser ejecutor exacto de sus órdenes, de sus instrucciones y de sus directrices. Su obediencia ha de entrañar una entrega absoluta e ilimitada, es decir, un actuar disciplinado. «La disciplina - nos dice A. Pinilla- inspira la conducta ordenada, refleja orden espiritual interior, acatamiento de la legítima jerarquización del mando. La acción disciplinada se caracteriza por el buen juicio y el buen ejemplo de quien manda y por el sentido de responsabilidad y de realidad con que actúan los que obedecen. Las personas disciplinadas - concluye - tienen una actitud mental que las capacita para pensar mejor y actuar pensando, trasladando a la acción los descubrimientos de su pensamiento crítico y creador» (8).

3. ${ }^{\mathrm{a}} \quad$ Conductor de sus hombres, de forma tal que suscite en ellos el entusiasmo preciso para cumplir su complejo cometido. Lo que demanda, en primer lugar, que el Jefe de la Policía posea una serie de cualidades que le hagan acreedor al respeto $y$ al afecto de aqué-

(7) Como complemento y ampliación de las ideas que se contienen en este subepígrafe, se puede acudir a F. Sierra y J. M. Garcfa PÉrEZ, en Guía de la Policia Municipal, Madrid, 1974, págs. 19 a 77.

(8) Obra citada, págs. 279-280. 
llos. Personalidad, vigor, equilibrio y flexibilidad se nos presentan como las notas más destacadas que deben caracterizarle. "El Jefe con verdaderas dotes de mando - destacan RoHRER, HIBLER y REPLOGE- sabe manejar a sus subordinados sin alardes de autoridad. Envuelve su fuerza, energía y autoconfianza en formas suaves impregnadas de tacto, delicadeza y suma finura. Tiene unos modales y una presencia de ánimo que imponen respeto a sus colegas y subordinados. $\mathrm{Y}$ al mismo tiempo posee un espíritu emprendedor y dinámico que le sitúa automáticamente en la categoría de Jefe» (9).

En segundo lugar, el Jefe de la Policía Municipal requiere tener confianza en si mismo, si pretende impulsar y conducir a los que están a sus órdenes. «El Jefe - afirma I. BALDINI- debe tener, ante todo, una gran confianza en su propia capacidad: si le falta ésta, no podrá obrar con la seguridad y determinación necesarias para asegurar la efectiva participación de todos en la actividad que dirige. La confianza en sí mismo es la consecuencia de la posesión de una habilidad suficiente para afrontar los diversos problemas que se pueden presentar en el cumplimiento de las propias funciones» (10).

En tercer término, el Jefe de la Policía Municipal, para conducir a sus hombres, ha de poseer equilibrio emocional, por cuanto, como nos advierte F. S. HaImaN, «la falta de estabilidad, seguridad y sano equilibrio personal producen deseos excesivos de dominación y dificultan al Jefe fomentar un ambiente de libertad o permitir que los demás se conduzcan con independencia» (11).

En cuarto lugar, el Jefe de la Policía Municipal ha de ser consciente de la importancia de la colaboración que le prestan sus Agentes, lo que implica tener presente la observación que formula G. S. ODIORNE: "El dirigente es una persona que tiene seguidores. Así, la valía de un Jefe está estrechamente relacionada con la de los hombres que trabajan para él y sus logros son fundamentalmente los de sus subordinados" (12).

En quinto término, el Jefe de la Policía Municipal ha de fomentar la participación de sus Agentes en las decisiones que adopte y ha de estimular la creación de un espíritu de equipo entre ellos. Actitud que responde a una necesidad sentida por el ser humano y que se pone de relieve por PARKer, KleEmeier y PARKer, al afirmar que

(9) Directivos del mañana, Salamanca, 1972, pág. 42.

(10) Cómo ser un buen Jefe, Madrid, 1972, pág. 92.

(11) Dirección de grupos, México, 1972, pág. 144.

(12) La dirección por objetivos, Barcelona, 1972, pág. 19. 
"dentro de cada uno de nosotros existe el deseo o motivo fundamental de ser un miembro útil, valioso y generalmente aceptado de nuestra comunidad o grupo» (13).

En sexto lugar, el Jefe de la Policía Municipal, para conducir bien a sus hombres ha de cuidar brindarles estimulos para entregarse al trabajo y ha de observar directamente su comportamiento en el mismo (14). En este sentido, B. F. Yulll advierte que «el Jefe aparece con dos funciones en la organización. Una de ellas consiste en mantener la motivación de sus subordinados. La otra en ver que el trabajo se realice de la manera más eficiente posible»(15).

$Y$ en último término, el Jefe de la Policía Municipal, para conducir bien a sus Agentes, ha de ser oportuno en sus decisiones (16). A este respecto, S. Escala nos dice que «los grandes hombres son hombres normales que tienen el acierto de hacer cosas convenientes en el momento oportuno y antes que los demás» (17).

En definitiva, el Jefe de la Policía Municipal, para poder conducir con éxito a sus hombres, precisa: tener personalidad, confiar en sí mismo, ser equilibrado, reconocer la trascendencia de la colaboración que aquéllos le prestan, fomentar su participación y espíritu de equipo, estimularles y ser oportuno, por cuanto, como advierte H. FRIEDRICHS, «el grado de éxito que se alcance en la fase de integración en la misión de brindar al colaborador las máximas oportunidades para su despliegue y para lograr que desarrolle la disposición óptima del rendimiento, dependerá también de modo decisivo del sistema de mando o dirección" (18).

4. ${ }^{\mathrm{a}}$ Respetuoso con el público, como consecuencia de reconocer en cada uno de sus integrantes:

- su condición de seres humanos poseedores de una dignidad que hay que saber tratar;

- su cualidad de miembros de una comunidad que precisa de ayuda $\mathrm{y}$ asistencia, $\mathrm{y}$

(13) Técnicas psicológicas modernas para jefes $y$ mandos intermedios, Barco lona, 1971, pág. 201.

(14) La importancia de estos estímulos la ponemos de manifiesto en nuestro Manual de Organización y Métodos. II. Dirección de Personal, Madrid, 1971, páginas 587 y sigs.

(15) Organización y Management, Barcelona, 1972, pág. 138.

(16) La problemática de las decisiones la estudiamos ampliamente en nuestro Manual de Organización y Métodos. I. Funciones Directivas, 2.: ed., Madrid, 1973, páginas 295 y sigs.

(17) Psicología para directivos, Barcelona, 1973, pág. 389.

(18) La moderna Dirección de Personal, Madrid, 1974, pág. 219. 
- su carácter de beneficiarios o usuarios de unos servicios municipales que existen, precisamente, para atender y satisfacer sus necesidades.

En definitiva, y en este aspecto, el Jefe de la Policía Municipal ha de ser consciente de que su misión se justifica en el grado en que es un auténtico servidor público, y en la medida en que realmente asiste, orienta y ayuda al público, al que ha de tratar con máximo cuidado, con especial corrección y con exquisito tacto.

5. ${ }^{\mathrm{a}}$ Ilusionado con su trascendente misión, por último, pues sólo teniendo una capacidad infinita de ilusión se puede desempenar este puesto, tan cargado de obligaciones y de servidumbres y tan poco compensado, por otra parte. En este sentido, se puede afirmar que si la retribución es menguada, de ordinario el reconocimiento y aprecio suelen ser aún menores, y, sin embargo, hay infinidad de personas que por su vocación desempeñan tal puesto con gran eficacia, y esto sólo es posible, precisamente, por la ilusión que les anima.

En conclusión, podríamos decir con D. D. K. David, que si el Jefe de la Policía Municipal quiere ser un directivo ideal, ha de reunir las siguientes cualidades:

- La capacidad de lograr que otras personas trabajen con eficacia.

- La capacidad de tomar decisiones a la luz de los hechos disponibles y bajo la urgencia del tiempo.

- La aceptación instintiva de responsabilidad.

- La comprensión de las fuerzas económicas, sociales y políticas que configuran los ambientes en los cuales actúa (19).

\section{NORMAS ESPECfFICAS}

El Jefe de la Policía Municipal, aparte de tener en cuenta las normas generales que acabamos de exponer, requiere al actuar en cada una de las tres áreas mencionadas, en las que se proyecta la autoridad del Alcalde, tener presentes, además, como anticipamos, otras normas específicas de cada una de dichas áreas. De ellas podemos resaltar como más trascendentes, pero no únicas, las siguientes:

(19) Tomado de M. L. MACE: Promoción y formación de ejecutivos, Barcelona, 1973, pág. 189. 


\section{A) En el plano del orden público (20).}

Cuando el Jefe de la Policía Municipal actúa en este campo, como proyección del Alcalde y representando a su autoridad, su comportamiento ha de caracterizarse por estas notas:

1..$^{\text {Reflexión } y ~ p r u d e n c i a . ~ E s ~ d e c i r, ~ a n t e s ~ d e ~ p a s a r ~ a ~ l a ~ a c c i o ́ n ~}$ el Jefe de la Policía ha de meditar suficientemente sobre qué es lo más conveniente que debe hacer, y una vez convencido sobre lo que ha de hacer, ha de llevarlo a cabo con mesura, con el fin de evitar mayores problemas que los que trata de resolver. Mesura que es siempre precisa, y sobre todo si se trata de emplear la fuerza, pues en este supuesto los efectos producidos pueden ser irreparables.

Ahora bien, la reflexión y prudencia no implican ni lentitud ni temor. Suponen, al contrario, el ejercicio de virtudes humanas y el empleo de potencias que la naturaleza nos ha proporcionado al convertirnos en seres racionales. La reflexión puede ser rápida, cuando se está acostumbrado a usar esta facultad; la prudencia no debe ser temor, sino sentido proporcionado de los medios que se emplean. "La prudencia - nos recuerda Figuerola Esquius- es, en palabras de Paul Claudel, la inteligente proa de nuestra esencia. La prudencia es conocida como la madre de la justicia y de la fortaleza" (21).

2. ${ }^{a}$ Decisión y tesón, es decir, la conducta del Jefe de la Policía debe ser de firmeza, propia de los hombres que tienen una idea cabal de su papel y de sus posibilidades. Y, además, de forma continuada y persistente, que se crece y agiganta ante las dificultades.

Por otra parte, y con relación a los demás con los que mantiene contacto, esta conducta tiene un gran efecto positivo, como lo advierte A. Prnilla cuando afirma que "el análisis de las situaciones de interacción humana pone de manifiesto que los integrantes del grupo, ante una autoridad vacilante, dubitativa y menoscabada, sienten desconfianza, inseguridad, desconcierto, desorientación y, por ende, inhibición en la acción" (22). El Jefe de la Policía Municipal precisa, pues, ser decidido y ser tesonero.

(20) Como complemento y ampliación del contenido de este subepígrafe, se puede acudir a M. Jordán Montañés, en Guia de la Policía Municipal, Madrid, 1974, página 195 a 252.

(21) La formación del capital humano, Madrid, 1971, pág. 52.

(22) Obra citada, pág. 302. 
La medida del grado en que se poseen ambas cualidades se pone de relieve cuando se sale airoso de las dificultades, y cuando éstas son una oportunidad para testimoniar la fortaleza de quien se enfrenta con ellas y las convierte en posibilidades de éxito. En este sentido, podemos distinguir claramente entre:

- quien ante cada oportunidad la transforma en una dificultad, el que hay que admitir que no es un Jefe de la Policía Municipal, y quien ante una dificultad la cambia en una oportunidad de triunfar; éste sí es un verdadero Jefe de la Policía Municipal.

3. Humanismo, pues no ha de olvidar que son seres humanos con los que se relaciona y los que pretende que se sometan a las exigencias del orden público. El Jefe de la Policía ha de tener presente en todo instante que las mujeres y los hombres con los que se relaciona y a los que ha de impulsar para que acepten las citadas demandas, son seres con ilusiones y con creencias; seres con prejuicios y con frustraciones y seres con intereses en juego que sienten amenazados. Circunstancias que hay que reconocer que son más propicias a dejarse influenciar por las pasiones y por los sentimientos, que por el juicio y por el razonamiento. Esto supone que su comportamiento se asienta más en lo emotivo e irracional, que en lo lógico y racional y, como consecuencia, pueden adoptar actitudes y posturas que en circunstancias normales serían inconcebibles. Y que, sin embargo, se presentan en estos estados de ánimo pasionales, influenciados por cualquier motivación. Ante ellos, el Jefe de la Policía precisa de una gran dosis de humanismo, que no entraña ni disculpa justificación ante las sorprendentes conductas que se pueden derivar de dichas actitudes; pero sí supone explicación de las mismas $\mathrm{y}$, como consecuencia, adopción de la postura más conveniente ante ellas. «En la vida de un directivo -nos dice E. T. ReEves-, la necesidad de gozar de una aguda sensibilidad para detectar las opiniones y sentimientos de sus subordinados aumenta de año en año. Debe saber percatarse con gran sensibilidad del impacto que el mismo produce en los demás si quiere alcanzar el nivel de cooperación imprescindible para el logro de sus objetivos" (23). Se requiere, pues, esta sensibilidad, este sentido humano en el ser, en el sentir y en el actuar del Jefe de la Policía Municipal, proyectado tanto en su relación con sus Agentes

(23) El desarrollo de los directivos, Salamanca, 1972, pág. 41. 
como en su relación con el público, y sobre todo cuando trata de imponerse un comportamiento dado, que es el requerido por las exigencias del orden público.

\section{B) En la esfera de las funciones representativas.}

Cuando el Jefe de la Policía Municipal actúa en esta esfera, el denominador común de su conducta especifica debe ser el de que, en todo momento, ha de ser consciente y tener presente que, si él es el símbolo externo o la manifestación de la autoridad corporativa municipal, ha de ser digno de tal representación y, como consecuencia, ha de extremar su conducta en los siguientes aspectos:

1. El decoro en su actuación de cualquier tipo y ante cualquier persona: sea vecino, sea visitante o sea turista. Ante todos ha de adoptar una conducta seria, digna y correcta.

2. La cortesía en el trato, cuidando sus expresiones, sus gestos y el tono de su voz, para agradarles y servirles de forma eficaz.

3. La distinción en el uniforme, así como en los modales que emplee, de forma que cause una impresión favorable en quien se relacione con él y en quien le observe, por cuanto hemos insistido que es el funcionario más visible de la Corporación.

4..$^{\circ}$ La comunicación eficaz, que no sólo consiste en saber informar sobre los datos que se le soliciten, sino también en lograr crear un clima de entendimiento y de solidaridad con el interlocutor, lo cual es cada día más necesario, como advierte L. A. APPLEY, cuando afirma que "muchas, muchas veces, gente situada en puestos de gran influencia ha dicho que la mayor necesidad de este mundo es una mejor comunicación entre las personas. Es muy difícil comprender por qué en una época en que la comunicación es más necesaria, y los medios para lograr la comunicación mayores que nunca en la historia y se siguen desarrollando rápidamente, los seres humanos están dedicando cada vez menos atención a una comunicación efectiva y teniendo cada vez menos habilidad para conseguirla» (24).

En definitiva, al personificar el Jefe de la Policía la autoridad municipal le obliga a mantener un comportamiento que ha de ser

(24) El nuevo concepto del Management, Madrid, 1971, pág. 149. 
modelo y ejemplo para los que le contemplen y para los que con él establezcan contacto, pues la impresión que cause y el signo que tenga la misma se convertirá, sin duda, en la opinión que merezca para tales observadores e interlocutores la respectiva Corporación, pues a ésta juzgarán a través de la conducta del Jefe de la Policía Municipal. Y en este sentido, no ha de olvidar que le son esenciales los rasgos de carácter a que se refieren ParKer, KLeemeier y Parker, cuando nos dicen que «incluyen una serie de características, tales como la honradez, la puntualidad, la laboriosidad, la amabilidad, la frugalidad, el tacto, la pulcritud y muchas otras» (25).

C) En el ámbito de la ordenación del tráfico, de la vigilancia del cumplimiento de las Ordenanzas municipales y del fomento de la armónica convivencia ciudadana (26).

Por último, su actuación en este campo tan complejo, que es además, precisamente, el más importante, el Jefe de la Policía Municipal tiene no sólo que observar las normas generales expuestas, sino también:

1. Tener el suficiente criterio para valorar cada conducta en orden a la reglamentación específica aplicable, en base a las circunstancias de cada caso. Criterio que ni es la rigidez, que conduce a lo irracional e incumplible, ni es la ausencia de límites. Supone la flexibilidad consciente que trata de someter los comportamientos a la normativa, sin violentar a las personas y sin desconocer ésta. Es, en definitiva, saber cuándo hay que ceder en lo secundario para conseguir lo principal, y saber también cuándo no se debe ceder en nada, para no perder todo. Es, en tesis de A. Pinilla, «el principio de la factibilidad, que consiste en el imperativo de alcanzar armonización inteligente entre lo que es deseable, de acuerdo al objetivo o finalidad, y lo que es posible de acuerdo a las circunstancias concretas de la situación. Este equilibrio entre lo deseable y lo posible es la condición de toda facti-

(25) Obra citada, pág. 188.

(26) Como complemento y ampliación de las ideas contenidas en este subepigrafe, se puede acudir a la citada Guia de la Policía Municipal, F. Collar SuárezInClán, J. M. LoPez Fernández, C. A. LOPEZ de Torres y L. Cabrera, págs. 257 a 339. y J. Mahfllo Santos, págs. 343 a 414 . 
bilidad, y como sentido de la oportunidad ve la solución cognoscitiva del problema dentro de las exigencias prácticas en términos de espacio, de tiempo...» (27).

2. Objetividad en su actuación, eliminando prejuicios, así como también ignorando simpatías y antipatías y no dejándose llevar nunca por los intereses que pueda haber en juego. El Jefe de la Policía Municipal está para servir a los intereses generales de la comunidad; no es, o no debe ser, un instrumento para defender determinados intereses o para perjudicar a otros. Esta objetividad necesaria la podemos relacionar con la precisa serenidad que se requiere en la actuación constante del Jefe de la Policía Municipal. «La serenidad - nos dice J. BASILE- constituye la medida del verdadero valor del Jefe, porque deriva de una cierta facultad de desapasionamiento, de cierta disposición interior que no depende de las circunstancias, sino que está íntimamente ligada a la fuerza del alma. Permite dar al esfuerzo, al mismo tiempo que todo su vigor, un matiz altruista y una prudencia extraída de valores superiores que la dilatan» (28).

3. Comprensión ante las posturas de los particulares, que en unos casos son de oposición, si piensan que han sido dañados; en otros de recelo, si temen que pueden ser perjudicados, y en otros de protesta, si entienden que se les da un trato que no merecen. En todos estos supuestos, y en otros muchos más que podríamos mencionar, el Jefe de la Policía ha de ser consciente - como hemos destacado anteriormente- de que están motivados por una mezcla de emociones e intereses que no son fáciles de definir, pero que sí son sencillos de entender. De aquí que su conducta deba ser la de comprensión, pero no de justificación, y menos de aceptación. Es decir, hay que comprender estas posturas y tratar de influenciarlas en sentido positivo, para lograr que cambie su signo; de forma que lo que es antagonismo pueda convertirse en colaboración, o al menos deje de ser oposición.

4. Eficacia en la actuación, no sólo conseguida realmente, sino también apreciada por el público. Es decir, el Jefe de la Policía Municipal no sólo ha de cuidar por atender adecuadamente al público y servirle en forma conveniente, tanto respecto al momento y lugar como a la cantidad y calidad del servicio prestado, sino

(27) Obra citada, págs. 310-311.

(28) La formación del lider 1980, Madrid, 1968, pág. 135. 
que además ha de lograr que el público advierta que se le sirve y valore positivamente tal servicio. En la medida en que se logre este reconocimiento, se conseguirá de hecho tener al público al lado del Jefe de la Policía y de sus Agentes.

5. Persuadir, más que imponer en su actuación, debe ser, por último, una meta importante en la conducta del Jefe de la Policía Municipal y de sus Agentes. En efecto, en su relación con el público en este ámbito, en el que la idea central y dominante es la obligación y la coacción, es esencial que se emplee más la vía del agrado y del convencimiento, es decir, de la persuasión, que el que se acuda al empleo de la imposición (29). Esta puede conseguir, a lo máximo, un pasivo cumplimiento; aquélla puede alcanzar una activa colaboración. Es cierto que la consecución de este propósito plantea problemas, pero el Jefe de la Policía Municipal no está -como hemos reiterado- para lo fácil; está para lo difícil y para lo imposible, y por ello creemos que es factible lograrlo, aunque demande un gran esfuerzo. Esfuerzo que, por otra parte, están acostumbrados a hacer, en las circunstancias más diversas y adversas, los Jefes de la Policía Municipal, y ello de forma habitual y casi rutinaria.

\section{EL JEFE DE LA POLICIA MUNICIPAL Y LAS RELACIONES PUBLICAS MUNICIPALES}

De la exposición que antecede se deduce -como pusimos de relieve en otra ocasión (30)- que frente a la concepción tradicional de considerar que la misión esencial que la Policía Municipal tenía asignada era la de vigilar el orden: anteriormente el referente a los peatones, hoy el de los vehículos en primer lugar y el de aquéllos en segundo término. $Y$ en ambos casos, cuidar que cuando se cometa una infracción se imponga una sanción. Sanción que, por otra parte, en algunos casos se abona y en otros, muchos más, queda pendiente. Frente a aquella concepción, repetimos, hay que propugnar una posición radicalmente distinta: la de que la misión, la gran misión de la Policía Municipal, es la de facilitar y promover la armónica convivencia de cuantos residen y de cuantos se hallan

(29) La problemática de la persuasión la estudiamos ampliamente en nuestro Manual de Organización y Métodos. III. Dinámica directiva, Madrid, 1974, págs. 257 y sigs.

(30) Las Relaciones Públicas en las ciudades, publicado en esta misma revista, núm. 171. 
de paso en la respectiva población. Y, al mismo tiempo, auxiliarles en aquellos casos en los que precisen ayuda del más variado tipo. Es decir, el Jefe de la Policía Municipal y sus Agentes han de convertirse en verdaderos amigos de todos con los que se relacionan por razón del servicio. Amistad entendida como sincero deseo de servir sin contraprestación alguna. Esto significa, por tanto, que los integrantes del Cuerpo de Policía Municipal han de ser las personas que inspiran confianza a todos, no los individuos que suscitan temor y provocan recelo. La importancia de la amistad en la vida actual la pone de relieve un insigne profesor español, Figuerola Esouius, cuando afirma que «en una época caracterizada por la indiferencia, el desagrado, la protesta y la violencia, es muy peligroso detenerse a considerar la necesidad de la justicia: de cumplir lo que se ha prometido y de dar lo que se debe. Con facilidad se califican de idealistas aquellos que se manifiestan en este sentido y con dificultad sus opiniones alcanzan difusión. ¡Cuán grande no será este peligro si nos atrevemos a afirmar que también es necesario dar otro género de cosas que cada uno de nosotros considera plenamente suyas, que no se refieren a sus bienes materiales o compromisos formales, sino que residen en el ámbito de lo más propio de la persona! La amistad es una de estas cosas. La amistad no es algo que se deba a otro en sentido estricto y no puede ser objeto de exigencia o reclamación. Pero su presencia o su ausencia tiene largas raíces y consecuencias insospechadas para la vida de una empresa. El análisis de su papel en la dinámica social nos descubre un mundo luminoso y olvidado" (31). Mundo luminoso y olvidado, en el que el Jefe de la Policía Municipal tiene un gran quehacer, si pretende convertirse, tanto él como sus Agentes, en un instrumento básico y en una pieza clave de la política de Relaciones Públicas municipales.

A este respecto, son significativas las siguientes manifestaciones de la «International City Manager's Association», que ratifican plenamente lo que hemos afirmado con anterioridad.

1. Los funcionarios de la Policía Municipal tienen un puesto de peculiar importancia desde el punto de vista de las Relaciones Públicas: en cierto sentido puede decirse que dichos funcionarios personifican el gobierno de la ciudad, ya que su trabajo requiere de ellos, en varias ocasiones, que representen la ley y los aspectos

(31) Obra citada, pág. 57. 
de servicio y reglamentos del gobierno de la ciudad. Es más, su uniforme y su presencia en todas partes de la ciudad los hacen servidores municipales particularmente visibles. Lo que haga el Jefe de la Policía Municipal y sus Agentes, y cómo lo hagan, es, consecuentemente, de vital importancia para el programa de Relaciones Públicas de la ciudad.

2. Las actividades reguladoras de la Policía son excepcionalmente importantes en el programa de Relaciones Públicas, ya que en su campo la Policía está tratando no únicamente con delincuentes, sino con ciudadanos ordinarios que se resienten del abuso de la autoridad. La reglamentación del tránsito es la más importante reglamentación policíaca desde el punto de vista de las Relaciones Públicas, ya que pone en contacto a la Policía Municipal con muchos ciudadanos. El Agente de Policía debe ser una caseta de información andante o motorizada para los visitantes y residentes locales (32).

Vemos, pues, como colofón, cuán trascendente es la actuación de la Policía Municipal en orden a la consecución de unas efectivas Relaciones Públicas municipales, de las que tan necesitadas están nuestras Corporaciones, para lograr del vecindario la aceptación ante sus decisiones y acuerdos y para conseguir su colaboración en el desarrollo de las actividades comunitarias.

En conclusión, el Jefe de la Policía Municipal se nos muestra como uno de los grandes pilares en los que se asienta la acción corporativa municipal. De la forma en que él sea y del modo cómo actúe depende el éxito o el fracaso de muchas actividades locales; su preparación, su dedicación y su entusiasmo son factores condicionantes esenciales en el desarrollo de su cometido.

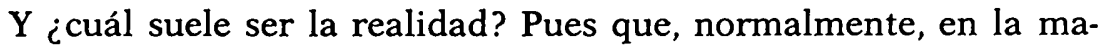
yoría, por no decir que en todos los casos, el Jefe de la Policía Municipal es, precisamente, este hombre entregado de lleno a su misión; la que saca adelante, supliendo la escasez de recursos y medios con su imaginación y con su ilusión. De tal forma, que en muchos supuestos parece como si nos encontrásemos ante "magos», pues hacen frente a las necesidades y resuelven los problemas que se van planteando, con medios que son prácticamente inexistentes o multiplicando los pocos que poseen.

Por ello, y para finalizar esta exposición, deseo una vez más rendir mi tributo de admiración a estos inteligentes y esforzados

(32) Técnica de la Administración municipal, México, 1963, pág. 639. 
hombres, que con su constante y callado trabajo laboran incansablemente en pro de una armónica convivencia ciudadana. Creo, además, que son acreedores a nuestro respeto, pues su acción permite llevar a cabo las decisiones de la autoridad municipal y son merecedores de nuestro afecto, por último, como testimonio de reconocimiento de la tarea bien hecha, que a menudo sólo les proporciona la satisfacción íntima del deber bien cumplido.

\section{CONCLUSIONES}

El análisis efectuado de la misión y actuación del Jefe de la Policía Municipal lo podemos sintetizar en los siguientes puntos:

1. La configuración legal del Alcalde como Delegado del Gobierno, como Presidente de la Corporación y como Jefe de la Administración municipal tiene, respectivamente, una triple incidencia en la actuación del Jefe de la Policía Municipal: en el orden público, en el plano representativo, en la ordenación del tráfico, en la vigilancia de la aplicación de las Ordenanzas municipales y en el fomento de la armónica convivencia vecinal.

2. El Jefe de la Policía Municipal representa a la autoridad municipal ante los vecinos, ante los visitantes y ante los turistas, y al mismo tiempo asume la responsabilidad del contacto más frecuente y de la relación primordial de estos grupos con la Corporación municipal fuera de la Casa Consistorial y al margen de los distintos servicios municipales.

3. La actuación del Jefe de la Policía Municipal está regida por una serie de normas que podemos diferenciar en dos grandes grupos: unas de carácter general y otras específicas de cada una de las áreas en las que se proyecta la triple dimensión del Alcalde.

4. Las normas dé carácter general se concretan en el saber, en el saber hacer y en el saber ser. El saber demanda conocimientos cada día mayores y cada vez más especializados. El saber hacer requiere actuar con perfección y con exactitud. El saber ser implica, a su vez, una triple exigencia: ser modelo como ciudadano; ser ejemplo como servidor municipal, y ser, en cuanto Jefe, leal y obediente a la Superioridad, conductor de sus hombres, respetuoso con el público e ilusionado con su misión.

5. Las normas específicas de la conducta del Jefe de la Policía 
Municipal, en el plano del orden público, constituyen también una triple exigencia: reflexión y prudencia, decisión y tesón y humanismo en su actuación.

6. Las normas específicas de la conducta del Jefe de la Policía Municipal, en la esfera de las funciones representativas, suponen para él un cuádruple reto: el decoro en su actuación, la cortesía en el trato, la distinción en su comportamiento y la comunicación eficaz en sus interrelaciones.

7. Las normas específicas de la conducta del Jefe de la Policía Municipal, en el ámbito de la ordenación del tráfico, de la vigilancia de las Ordenanzas municipales y del fomento de la armónica convivencia vecinal, entrañan para él un quíntuple desafío: precisa tener el suficiente criterio, objetividad en la actuación, comprensión ante las posturas de los particulares, eficacia en la acción y utilizar más la persuasión que la imposición en la relación con ellos.

8. Finalmente, el Jefe de la Policía Municipal es una pieza clave dentro de la política de Relaciones Públicas municipales, en cuanto es el servidor municipal más visible y que más se relaciona con los vecinos, con los visitantes y con los turistas, con lo cual su comportamiento constituye un factor esencial en la creación de una imagen favorable de la Corporación. 
REVL-1974, núm. 182. CARRASCO BELINCHON, JULIAN. EL JEFE DE LA POLICIA MUNICIPAL... REVL-1974, núm. 182. CARRASCO BELINCHON, JULIAN. EL JEFE DE LA POLICIA MUNICIPAL... 